Rev. Biol. Trop. 52(1): 1-17, 2004

www.ucr.ac.cr www.ots.ac.cr www.ots.duke.edu

ARTÍCULO ESPECIAL / SPECIAL PAPER

\title{
¿Cuáles son las revistas, libros y personas más influyentes en la biología latinoamericana?
}

\author{
Julián Monge-Nájera ${ }^{1,2}$, Catalina Benavides-Varela ${ }^{1} \&$ Bernal Morera ${ }^{1}$ \\ 1 Revista de Biología Tropical, Universidad de Costa Rica, 2060 San José, Costa Rica, rbt@ cariari.ucr.ac.cr \\ 2 Dirección de Producción Académica, Universidad Estatal a Distancia, San José, Costa Rica, jmonge@ uned.ac.cr \\ Presentado 08-I-2004. Corregido 01-III-2004.
}

\begin{abstract}
A survey was distributed by email to 553 biologists who study the Neotropics, in order to identify the journals, books and researchers with the greatest influence over Latin American biology. The biologists' database of the Revista de Biología Tropical was used to obtain their addresses. One third of them answered. The Revista de Biología Tropical is considered the most influential journal in the region. The majority of other influential journals are published in developed countries. The thematic distribution of answers, as well as independent assessments found in the literature, indicate that these and other survey results are not biased by the use of the journal's database. By subject, marine and ecological journals are the most influential. In contrast with American science, there are no researchers or books that clearly dominate the field. These results hint to the subjectivity of many awards and qualifications and possibly reflect a lack of tradition regarding appearance of local scientists in the mass media, the small capacity of world wide diffusion for local research and the low priority of science in the Iberoamerican culture. Latin American journals should improve, specially through efficient communication with authors, stringent rejection of inferior manuscripts and through widespread and timely distribution. The marked dominance by male researchers may reflect the lower number of women in the field, and social inequality. Despite the absence of "superstars", there was a correlation: most scientists in the "list of outstanding researchers" were from large countries. The publication of the most influential journal in one of the smallest countries of the region might reflect the relatively long period of existence of the Revista (half a century), the lack of other alternatives in the region and the journal's inclusion in international indices. Recommendations for Latin American science include a selection of the best journals to receive financial support and the establishment, with help from the mass media, of a group of selected researchers as role models for the new generations.
\end{abstract}

Key words: Latin American science, outstanding researchers, influential books, main journals, sexual inequality.

Al menos desde el siglo XV existe literatura que describe como las naciones económica y militarmente dominantes de cada época dominan también el aparato cultural, incluyendo la investigación sobre la naturaleza (Morehouse 1984), de lo cual es un ejemplo contemporáneo el que las revistas Nature y Science sean las que reciban alto puntaje en los índices de citas y mayor atención en los medios internacionales de comunicación (Calvo 2003). A su vez, estos medios de comunicación están dominados también por los países más poderosos (Fuentes 1997). Sin embargo, estas situaciones son típicamente temporales, lo que brinda a revistas de países más pequeños la esperanza de un futuro mejor y la posibilidad de escapar al patrón de dominación mediante un esfuerzo por servir a los intereses regionales (Monge-Nájera 2002, 2003, Redondo 2003). Las revistas que tienen éxito en este objetivo se vuelven influyentes en la vida académica de la especialidad y la región a que se refieren.

Además de las revistas, las personas dedicadas a la investigación reciben influencias importantes de sus maestros y de algunos de los tantos libros que leen durante su formación 
científica. Dos ejemplos ampliamente conocidos de esto son el de Louis Pasteur y el de Louis Leakey. Louis Pasteur inició sus estudios superiores con intereses en el arte y la educación, pero las lecciones del químico Dumas lo hicieron redirigir su interés hacia el área de la ciencia (Kruif 1954). Louis Leakey, ampliamente conocido por sus aportes en la reconstrucción de la historia evolutiva del ser humano, afirmó que lo hizo inspirado por The Descent of Man de Charles Darwin (Cole 1975). Igualmente, otros libros como Microbe Hunters han sido mencionados como inspiración por muchos investigadores (Summers 1998).

Este estudio analiza los resultados de una encuesta, distribuida entre investigadores e investigadoras de la biología neotropical, sobre las revistas, personas y libros que más han influido en su trabajo, y sobre cuáles consideran que son las personas y las revistas biológicas latinoamericanas más sobresalientes.

\section{MATERIALES Y MÉTODOS}

Se envió por correo electrónico una encuesta (Apéndice 1) a 553 personas dedicadas a la biología tropical, según la base de datos de la Revista de Biología Tropical.

\section{RESULTADOS}

Revistas más influyentes en la labor científica: La encuesta fue respondida por 152 personas (27\% de las consultadas), quienes indicaron que las revistas científicas que más influyen en su trabajo son Revista de Biología Tropical ( $\mathrm{N}=25$ respuestas), Ecology (14), Marine Biology (12), Marine Ecology Progress Series (12), Bulletin of Marine Science (10), Hydrobiologia (9), Coral Reefs, Journal of Plankton Research y Nature (8 casos cada una), Biotropica, Conservation Biology, Limnology and Oceanography y Science (7 casos cada una), American Fern Journal, Aquaculture, Crustaceana y Journal of Herpetology (5 casos cada una). Muchas otras revistas fueron citadas, pero con menor frecuencia (Cuadro 1).

Investigadoras e investigadores más influyentes: Las respuestas incluyeron a una gran cantidad de personas como científicos (as) más destacados (as) de América Latina (Cuadro 2). Ninguna de estas personas obtuvo un número de respuestas que le permitiera destacarse significativamente del resto. Sin embargo, se encontraron tendencias en cuanto al sexo, el país y la especialidad:

Un $88 \%$ de las 184 personas mencionadas cuyo sexo pudo identificarse con base en el nombre son hombres. La mayoría de estas personas sobresalientes son de México (48), Brasil (40), Argentina (26) y Costa Rica (16). Otros países mencionados en la nacionalidad de personajes sobresalientes fueron Colombia (11), Chile (10), Venezuela (9) y EEUU (8). Los demás países tuvieron una frecuencia inferior a 5 en las respuestas.

Las especialidades más mencionadas para personas influyentes fueron Zoología (38), Ecología (37), Taxonomía y Sistemática (12), seguidas de Biomedicina (12), Genética (11), Oceanografía (9), Botánica (8) y Bioquímica y Biología Molecular (7). Otras especialidades fueron mencionadas menos de cuatro veces.

Libros más influyentes: Ninguno de los libros científicos mencionados como más influyentes en el trabajo de investigadoras e investigadores de la biología neotropicales dominó marcadamente la lista (Cuadro 3), pero hubo tendencias relacionadas con el idioma y el tema:

Predominaron los libros en inglés (82\%), seguidos lejanamente por los publicados en español $(16 \%)$, francés $(2 \%)$ y portugués $(0.4 \%$, de un total de 282 libros).

Los temas predominantes de estos libros influyentes son Zoología (73), Ecología (37), Botánica (26), Oceanografía (20) y Taxonomía (15). Los libros de otras especialidades fueron citados menos de nueve veces.

Principales revistas científicas de América Latina: Quienes respondieron la encuesta opinaron que las principales revistas científicas de América Latina son: Revista de 
CUADRO 1

Frecuencia de respuestas a la pregunta sobre las tres revistas científicas que más influyen

en el trabajo de las personas encuestadas

TABLE 1

Frecuency for answers to the question "Which are the three scientific journals with the greatest influence on your work?"

Revista

\# Respuestas

Revista

\# Respuestas

Acta Botánica Mexicana

Agriculture, Ecosystems and Enviroment

Ecology Letters

Agroforestry Systems

American Fern Journal

American Journal of Botany

American Journal of Human Genetics

American Journal of Pathology

American Journal of Physiology and Cell Biology

American Journal of Tropical Medicine and Hygiene

American Museum Novitates

American Naturalist

Animal Behavior

Annals of the Missouri Botanical Garden

Antimicrobial Agents and Chemotherapy

Applied and Enviromental Microbiology

Aquaculture

Aquaculture International

Aquaculture Research

Aquatic Botany

Aquatic Ecosystem Health and Management

Aquatic Insects

Archives fur Hidrobiologie

Auk

Australian Journal of Botany

Behavioral Ecology and Sociobiology

Biochemistry

Biodiversity and Conservation

Biological Conservation

Biota (Instituto Humbolt)

Biotropica

Brenesia

Britonnia

Bulletin of Environment, Contamination and Toxicology

Bulletin of Marine Science

Bulletin of the Florida Museum of Natural History

Caldasia

Canadian Journal of Botany

Canadian Journal of Fisheries and Aquatic Sciences

Caribean Journal of Sciences

CBP

Ciencias Marinas

Cladistics

Coastal and Shelf Sciences

Conservation Biology

Conservation Genetics

Copeia

Coral Reefs

Crustaceana

Deep Sea Research

Die Orchidee (Hamburg)

Ecology

Ecology Progress Series
Ecological Aplications

Ecotoxicology and Enviromental Safety

Endocrinology

Entomologia Experimentalis et Applicata

Entomological News

Enviromental Biology of Fishes

Enviromental Contamination and Toxicology

Enviromental Entomology

Enviromental Management

Enviromental Toxicology

Estuaries

Estuarine, Coastal and Shelf Science

Evolution

Fern Gazette

Fisheries Bulletin

Fisheries Management and Ecology $\quad 2$

Fisheries Research

Fisheries Science

Folia Geobotanica

Forensic Science International

Forest Ecology and Management

Forest Science

Freshwater Biology

Gayana (Zoología)

General and Comparative Endocrinology

Genetics

Gulf and Caribean Research

Herpetologica

Herpetological Review

Hidrobiologica

Human Molecular Genetics

Hydrobiologia

IAWA Journal

Iberus

Insectes Sociaux

Investigación y Ciencia

JEMBE

Journal of Agriculture and Food Chemistry

Journal of Animal Ecology

Journal of Aquaculture

Journal of Arachnology

Journal of Biogeography

Journal of Biological Chemistry

Journal of Crustacean Biology

Journal of Ecology

Journal of Ecotoxicology and Enviromental Safety

Journal of Entomology

Journal of Essential Oil Research

Journal of Experimental Marine Biology and Ecology 
CUADRO 1 (...continuación)

Frecuencia de respuestas a la pregunta sobre las tres revistas científicas que más influyen

en el trabajo de las personas encuestadas

TABLE 1 (...continued)

Frecuency for answers to the question "Which are the three scientific journals with the greatest influence on your work?"

Revista \# Respuestas Revista \# Respuestas

Journal of Experimental Marine Ecology and Biology 1

Journal of Fish Biology

Journal of Forensic Sciences

Journal of Freshwater Research

Orchids

Oryx

Pacific Science

Pan-Pacific Entomology

Pfugger Arch - European Journal of Physiology 1 Phycologia 1

Journal of Heredity

Journal of Herpetology

Journal of Hymenoptera Research

Journal of Insect Behavior

Phytochemistry

Phytopatology

Plant and Soil

Journal of Invertebrate Pathology

Plant Cell, Tissue and Organ Culture

Journal of Mammalogy

Journal of Marine Biology

Journal of Medical Entomology

Plant Disease

Plant Ecology

Plant Physiology

Journal of Natural History

Journal of Paleolimnology

Journal of Parasitology

Journal of Plankton Research

Journal of Raptor Research

Journal of Shellfish Research

Journal of Shellfish Research

Journal of the American Mosquito Control Association

Journal of the Kansas Entomological Society

Journal of the Lepidopterist Society

Journal of the North American Benthological Society

Journal of the World Aquaculture Society

Journal of Tropical Ecology

Journal of Vegetation Sciences

Lakes and Reservoirs Management

Landscape Ecology

Limnology and Oceanography

Marine Biology

Marine Biology Progress Series

Marine Ecology

Marine Ecology Progress Series

Memorias do Instituto Oswaldo Cruz

MEPS

Molecular Ecology

Molecular Phylogenetics and Evolution

Mutation Research

Mycologia

Mycotaxon

Nature

Nature Biotechnology

Naturwissenschaften

Nauplius

Nautilus

New York Botanical Garden Memoirs

Odonatologica

Oecologia

Proceedings of the Entomological Society of Washington

Proceedings of the National Academy of Sciences USA 2

Proceedings of the Zoological Society of Washington 1

Quaternary Research

Revista Brasileira de Entomologia

Revista Brasileira de Zoología

Revista Chilena de Historia Natural

Revista de Biología Marina y Oceanografía (Valparaíso)

Revista de Biología Tropical

Revista de la Sociedad Entomológica Argentina $\quad 1$

Revista Ibérica de Aracnolgía

Revista Peruana de Entomología

Science

Scientia Marina

Selbyana

Sociobiology

Soil Biology and Biochemistry

Studia Dipterologica

Studies on Neotropical Fauna and Enviroment

Systematic Biology

Systematic Botany

Systematic Entomology

Systematic Zoology

Toxicon

Transactions of the American Entomological Society

Tree

Tree Physiology

Trends in Ecology and Evolution

Trends in Pharmacology

Tropical Lepidoptera

Wetlands

Wetlands Ecology and Mamagement

Wildlife Management

Zoo Biology

Zoological Journal of the Linnean Society of London Zoological Medicine

Oikos 
CUADRO 2

Científicos (as) más destacados (as) de América Latina según las personas consultadas (número de casos)

TABLE 2

Most outstanding Latin American scientists according to the survey (includes foreigners that normally work in the region)

Científico destacado/País/Área

\# Respuestas

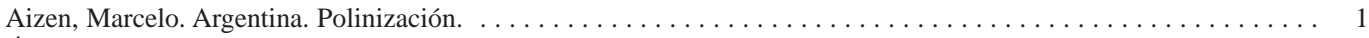

Álvarez Solórzano, Ticul. México. Mastozoología. $\ldots \ldots \ldots \ldots \ldots \ldots \ldots \ldots \ldots \ldots \ldots \ldots \ldots \ldots \ldots \ldots 1$

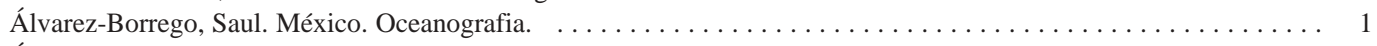

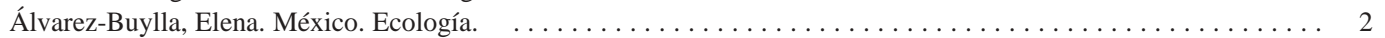

Amaro Pinheiro, Marcelo Antonio. Brasil. Carcinología. $\ldots \ldots \ldots \ldots \ldots \ldots \ldots \ldots \ldots \ldots \ldots \ldots \ldots \ldots \ldots$

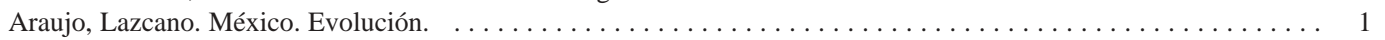

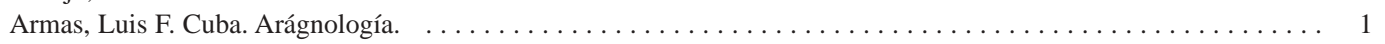

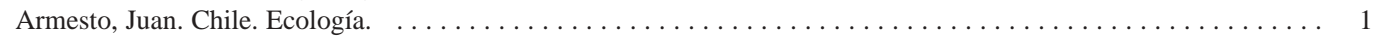

Arratia, Gloria. Chile. Evolución. $\ldots \ldots \ldots \ldots \ldots \ldots \ldots \ldots \ldots \ldots \ldots \ldots \ldots \ldots \ldots \ldots \ldots \ldots \ldots \ldots \ldots \ldots$

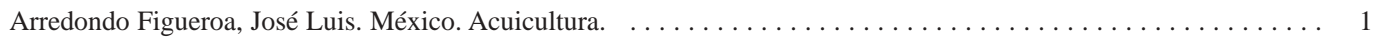

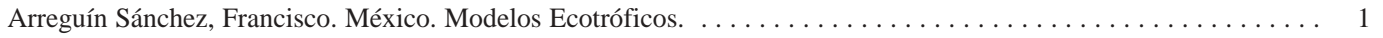

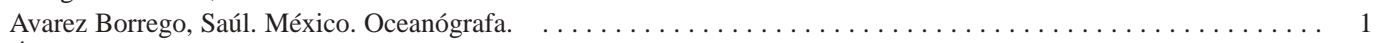

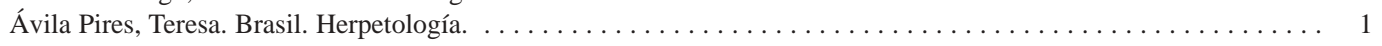

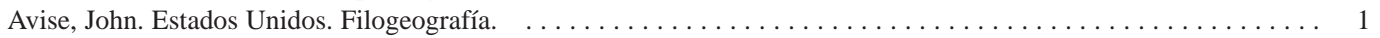

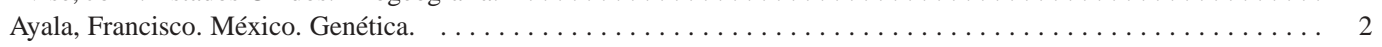

Bachmann, Axel. Argentina. Nomenclatura Zoológica. $\quad \ldots \ldots \ldots \ldots \ldots \ldots \ldots \ldots \ldots \ldots \ldots \ldots \ldots \ldots \ldots \ldots$

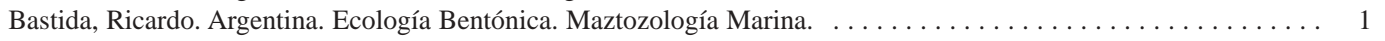

Becker, Victor. Brazil. Entomología (Lepidópteros Nocturnos). $\ldots \ldots \ldots \ldots \ldots \ldots \ldots \ldots \ldots \ldots \ldots \ldots \ldots \ldots 2$

Bernal, Patricio. Chile. Zooplancton y Pesquerías $\ldots \ldots \ldots \ldots \ldots \ldots \ldots \ldots \ldots \ldots \ldots \ldots \ldots \ldots \ldots \ldots \ldots$

Berovides, Vicente. Cuba. Biología Evolutiva. $\ldots \ldots \ldots \ldots \ldots \ldots \ldots \ldots \ldots \ldots \ldots \ldots \ldots \ldots \ldots \ldots \ldots$

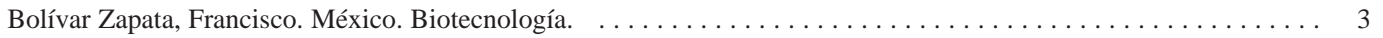

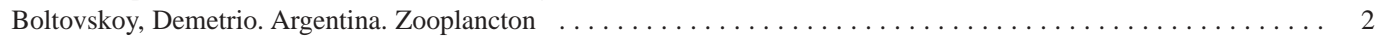

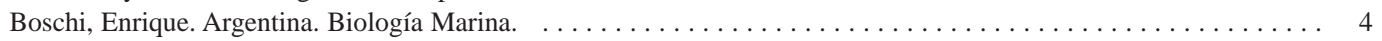

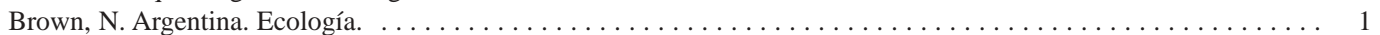

Budowski, Gerardo. Costa Rica. Agroforestería. $\ldots \ldots \ldots \ldots \ldots \ldots \ldots \ldots \ldots \ldots \ldots \ldots \ldots \ldots \ldots \ldots \ldots$

C. Martins, Marcio R. Brasil. Historia Natural y Ecología de Reptiles. $\ldots \ldots \ldots \ldots \ldots \ldots \ldots \ldots \ldots \ldots \ldots \ldots \ldots$

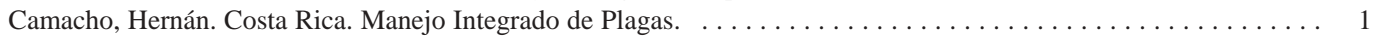

Campbell, Jonathan. Estados Unidos/Guatemala. Herpetología. $\ldots \ldots \ldots \ldots \ldots \ldots \ldots \ldots \ldots \ldots \ldots \ldots \ldots \ldots \ldots$

Cantera, Jaime. Ecología de Estuarios. $\ldots \ldots \ldots \ldots \ldots \ldots \ldots \ldots \ldots \ldots \ldots \ldots \ldots \ldots \ldots \ldots \ldots \ldots \ldots \ldots \ldots$

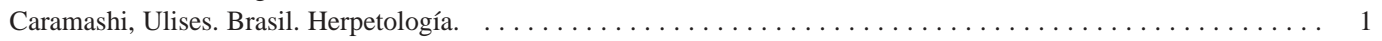

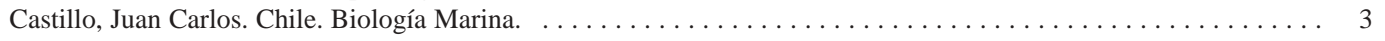

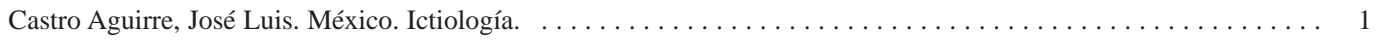

Cazzaniga, Néstor. 1 Cei, José María. Argentina/Portugal/Italia. Herpetología. $\ldots \ldots \ldots \ldots \ldots \ldots \ldots \ldots \ldots \ldots \ldots$

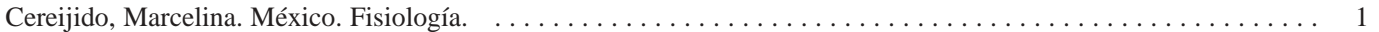

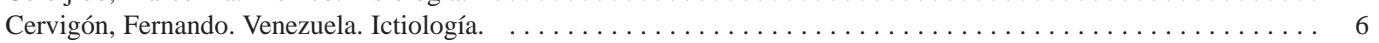

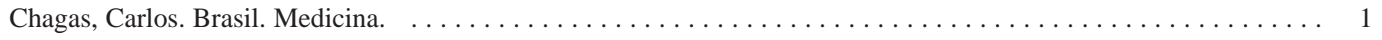

Chávez, Francisco. Perú. Biología / Geología Marina / Toxicología. $\ldots \ldots \ldots \ldots \ldots \ldots \ldots \ldots \ldots \ldots \ldots \ldots \ldots 2$

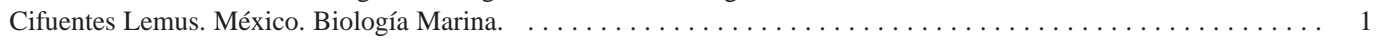

Clark, David \& Clark Debora. Ecología Forestal. $\ldots \ldots \ldots \ldots \ldots \ldots \ldots \ldots \ldots \ldots \ldots \ldots \ldots \ldots \ldots \ldots \ldots \ldots$

Claro Madruga, Rodolfo. Cuba. Ecología de Peces. $\ldots \ldots \ldots \ldots \ldots \ldots \ldots \ldots \ldots \ldots \ldots \ldots \ldots \ldots \ldots \ldots$

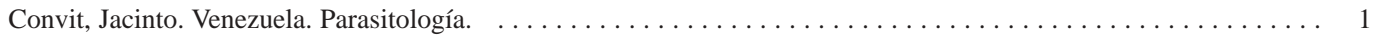

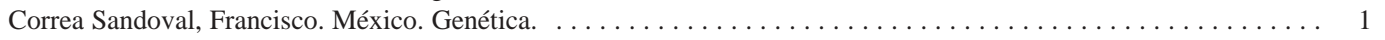

Corredor, Jorge. Colombia. Oceanografía Química. $\ldots \ldots \ldots \ldots \ldots \ldots \ldots \ldots \ldots \ldots \ldots \ldots \ldots \ldots \ldots \ldots \ldots$

Cortes, Jorge. Costa Rica. Arrecifes de Coral y Geología Marina. $\ldots \ldots \ldots \ldots \ldots \ldots \ldots \ldots \ldots \ldots \ldots \ldots \ldots$

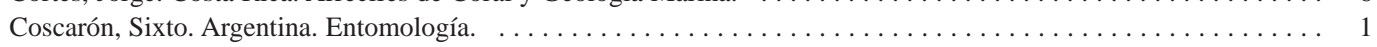

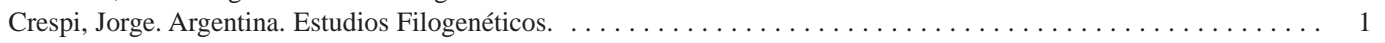

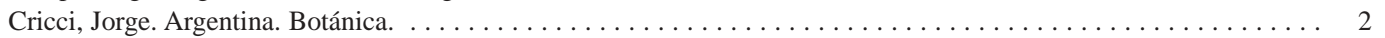

Crisci, Jorge Victor. Argentina. Taxonomía y Biogeografía. $\ldots \ldots \ldots \ldots \ldots \ldots \ldots \ldots \ldots \ldots \ldots \ldots \ldots \ldots \ldots$

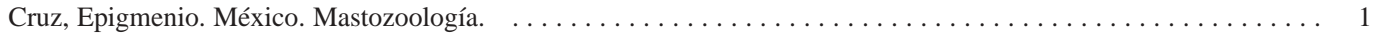

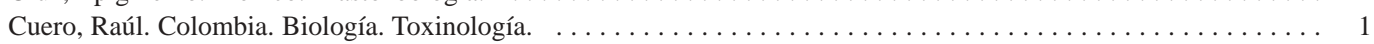


CUADRO 2 (...continuación)

Científicos (as) más destacados (as) de América Latina según las personas consultadas (número de casos)

TABLE 2 (...continued)

Most outstanding Latin American scientists according to the survey (includes foreigners that normally work in the region)

Científico destacado/País/Área

\# Respuestas

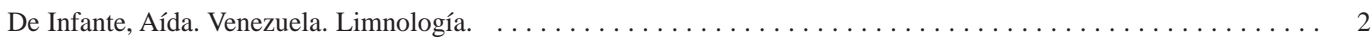

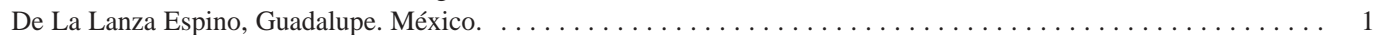

De La Sota, Elías Ramón. Argentina. Taxonomía de Pteridófitas. $\quad \ldots \ldots \ldots \ldots \ldots \ldots \ldots \ldots \ldots \ldots \ldots \ldots \ldots \ldots$

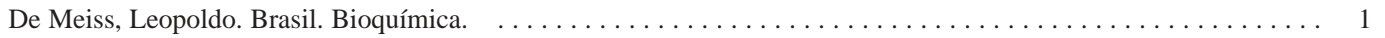

De Melo Sene, Fabio. Brasil. Genética Evolutiva. $\ldots \ldots \ldots \ldots \ldots \ldots \ldots \ldots \ldots \ldots \ldots \ldots \ldots \ldots \ldots \ldots \ldots$

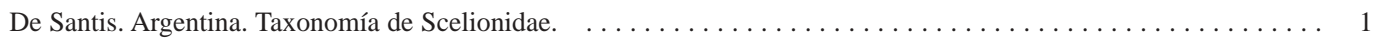

De Sousa, Wanderley. Brasil. Biólogía Celular. $\ldots \ldots \ldots \ldots \ldots \ldots \ldots \ldots \ldots \ldots \ldots \ldots \ldots \ldots \ldots \ldots \ldots \ldots \ldots$

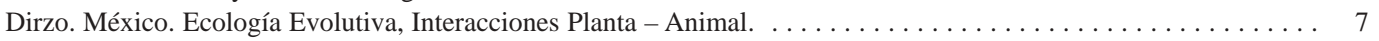

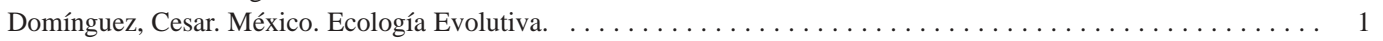

Druker Colin, René. México. Fisiología Celular. $\ldots \ldots \ldots \ldots \ldots \ldots \ldots \ldots \ldots \ldots \ldots \ldots \ldots \ldots \ldots \ldots \ldots \ldots$

Duellman, William. Estados Unidos. Herpetología. $\ldots \ldots \ldots \ldots \ldots \ldots \ldots \ldots \ldots \ldots \ldots \ldots \ldots \ldots \ldots \ldots \ldots \ldots$

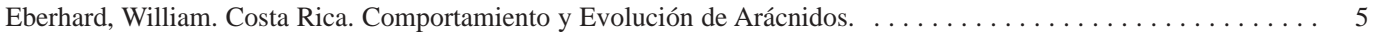

Eguiarte Fruns, Luis Enrique. México. Genética de Poblaciones. $\ldots \ldots \ldots \ldots \ldots \ldots \ldots \ldots \ldots \ldots \ldots \ldots \ldots \ldots$

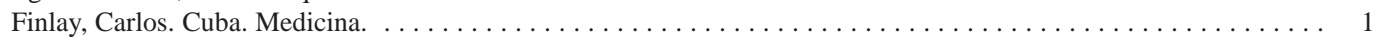

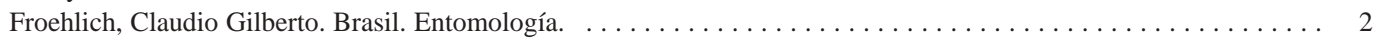

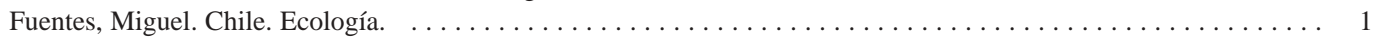

Gajardo, Gonzalo. Chile. Genética de Artemia. $\ldots \ldots \ldots \ldots \ldots \ldots \ldots \ldots \ldots \ldots \ldots \ldots \ldots \ldots \ldots \ldots \ldots \ldots$

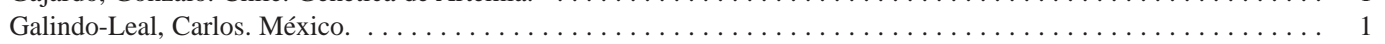

Garzón, Jaime, Ferreira. Colombia. Arrecifes Coralinos, Peces de Arrecifes, Enfermedades de Corales. . . . . . . 1

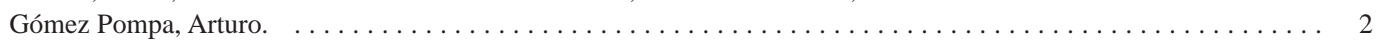

Gómez Poyou, Armando. México. Bioquímica. $\ldots \ldots \ldots \ldots \ldots \ldots \ldots \ldots \ldots \ldots \ldots \ldots \ldots \ldots \ldots \ldots \ldots \ldots$

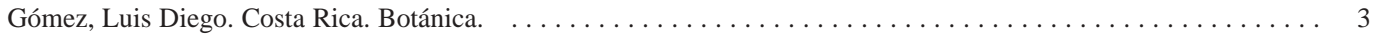

González Sansón, Gaspar. Cuba. Especialidad Ecología y Pesquerías. $\ldots \ldots \ldots \ldots \ldots \ldots \ldots \ldots \ldots \ldots \ldots \ldots \ldots \ldots$

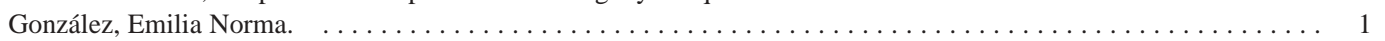

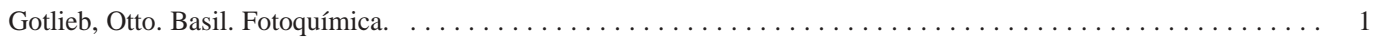

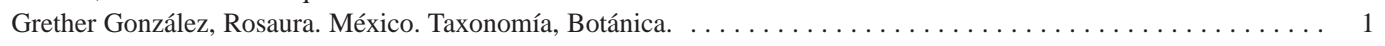

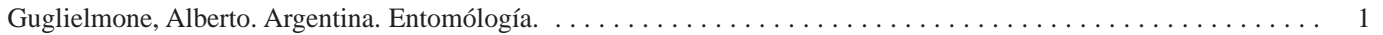

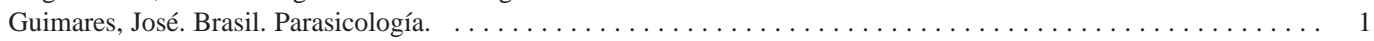

Guzman, Hector. Panamá. Ecología de Arrecifes Coralinos. $\ldots \ldots \ldots \ldots \ldots \ldots \ldots \ldots \ldots \ldots \ldots \ldots \ldots \ldots . \ldots$

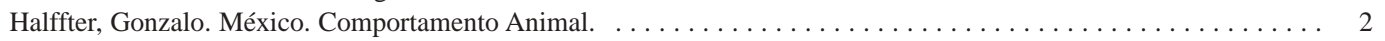

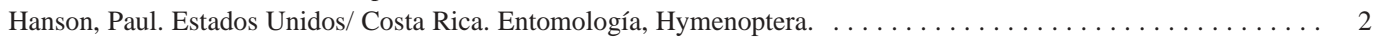

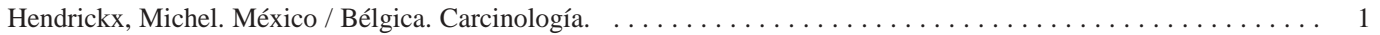

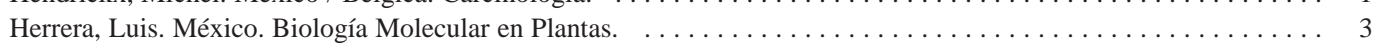

Hoenigsberg, Hugo. Colombia. Genética de Poblaciones. $\ldots \ldots \ldots \ldots \ldots \ldots \ldots \ldots \ldots \ldots \ldots \ldots \ldots \ldots \ldots \ldots \ldots$

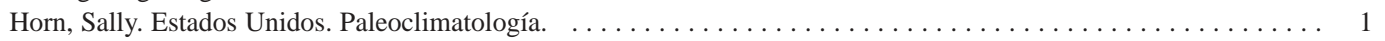

Iglesias, Roberto. México. Arrecifes Coralinos $\quad \ldots \ldots \ldots \ldots \ldots \ldots \ldots \ldots \ldots \ldots \ldots \ldots \ldots \ldots \ldots \ldots \ldots \ldots$

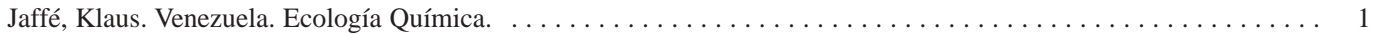

Jaksic, Fabián. Chile. Ecología de Aves y Mamíferos Carnívoros. $\ldots \ldots \ldots \ldots \ldots \ldots \ldots \ldots \ldots \ldots \ldots \ldots \ldots . \ldots \ldots$

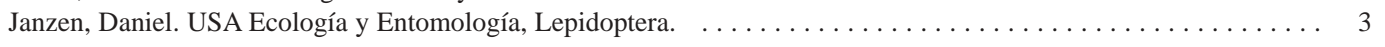

Jiménez, Jorge. Costa Rica. Biología de Manglares. $\quad \ldots \ldots \ldots \ldots \ldots \ldots \ldots \ldots \ldots \ldots \ldots \ldots \ldots \ldots \ldots \ldots$

Junk. Brasil. Ecología de Plantas en Humedales. $\ldots \ldots \ldots \ldots \ldots \ldots \ldots \ldots \ldots \ldots \ldots \ldots \ldots \ldots \ldots \ldots \ldots \ldots$

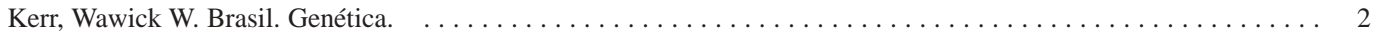

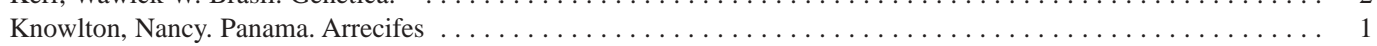

Latorre, Ramón. Chile. Biología Molecular, Canales Iónicos. $\ldots \ldots \ldots \ldots \ldots \ldots \ldots \ldots \ldots \ldots \ldots \ldots \ldots \ldots$

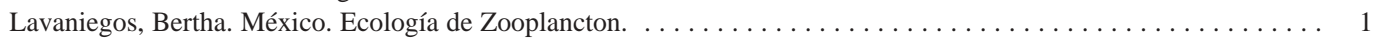

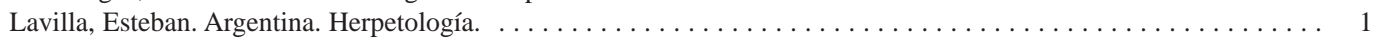

Leal, José H. Brasil. Zoología de Invertebrados, moluscos. $\quad \ldots \ldots \ldots \ldots \ldots \ldots \ldots \ldots \ldots \ldots \ldots \ldots \ldots \ldots \ldots$

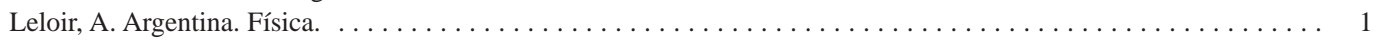

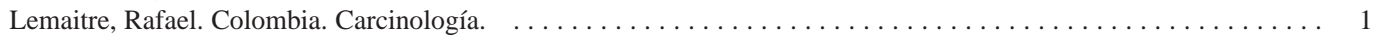

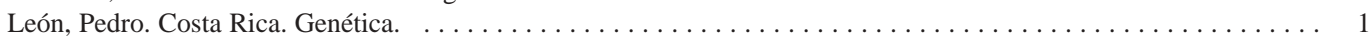


CUADRO 2 (...continuación)

Científicos (as) más destacados (as) de América Latina según las personas consultadas (número de casos)

TABLE 2 (...continued)

Most outstanding Latin American scientists according to the survey (includes foreigners that normally work in the region)

Científico destacado/País/Área

\# Respuestas

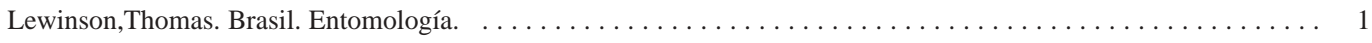

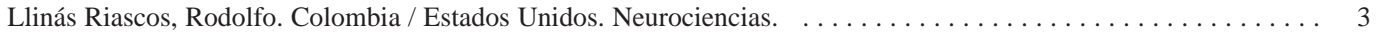

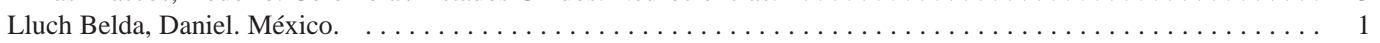

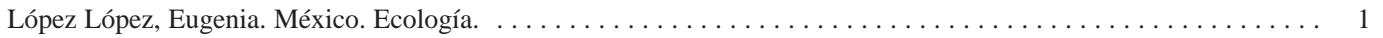

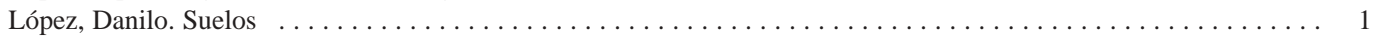

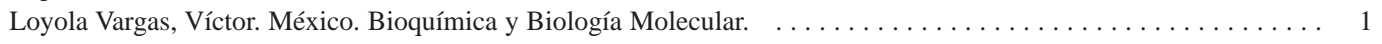

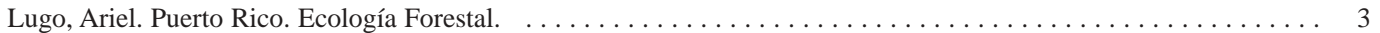

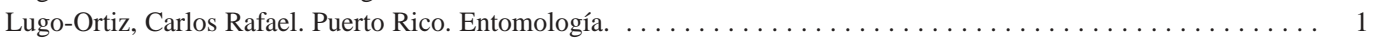

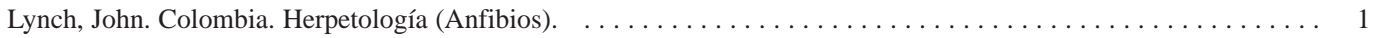

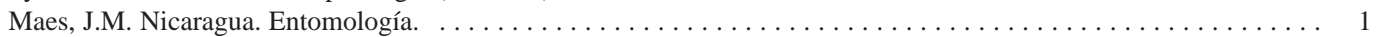

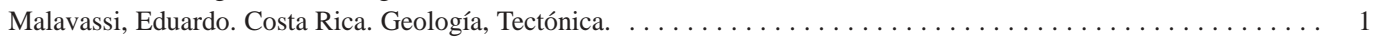

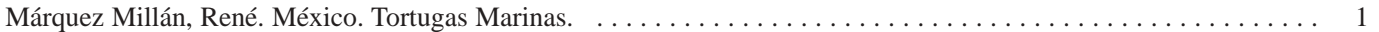

Martinez Ramos, Miguel. México. Ecologia Tropical de Plántulas. $\ldots \ldots \ldots \ldots \ldots$

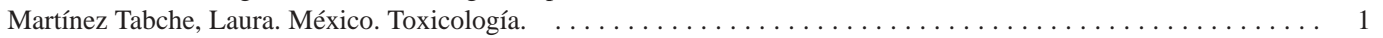

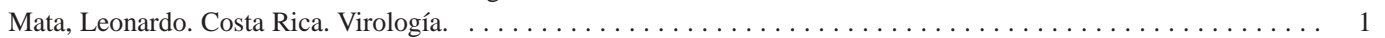

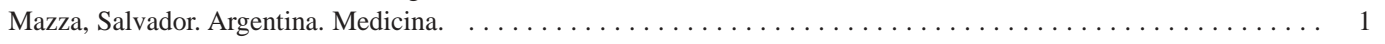

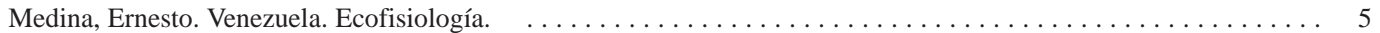

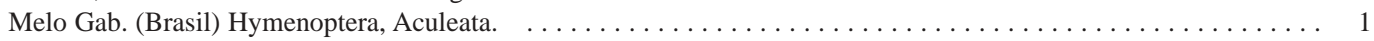

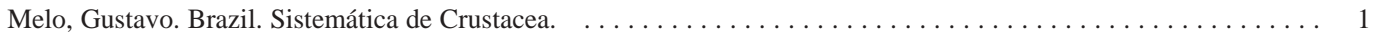

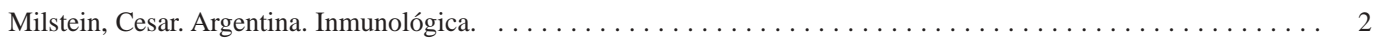

Molina, Mario. México. Investigación En Los Hoyos De Ozono (NASA) $\ldots \ldots \ldots \ldots$

Monge Najera, Julián. Costa Rica. Ecología (Onicóforos). $\ldots \ldots \ldots \ldots \ldots \ldots$

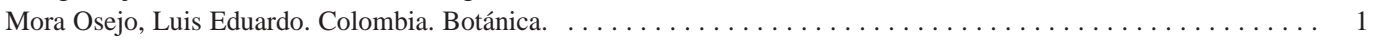

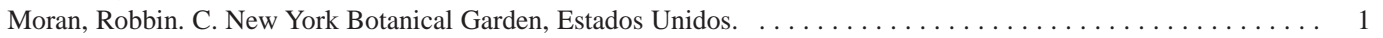

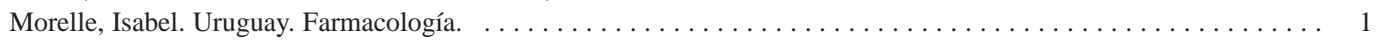

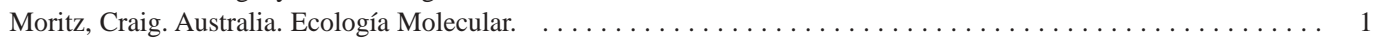

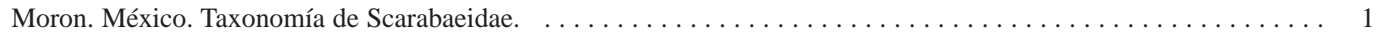

Morrone, Juan José. Argentina. Biogeografía y Taxónomía. $\ldots \ldots \ldots \ldots \ldots \ldots \ldots \ldots \ldots$

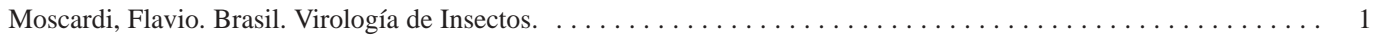

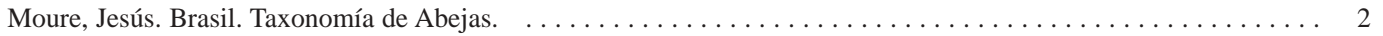

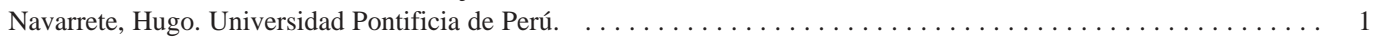

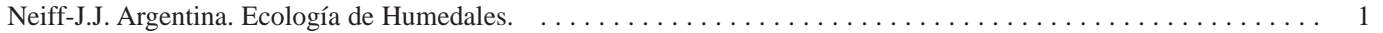

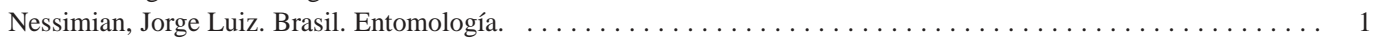

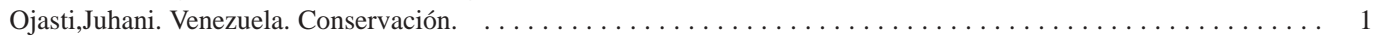

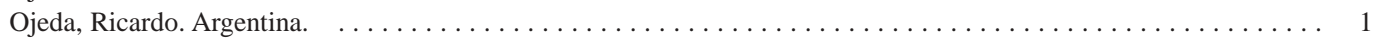

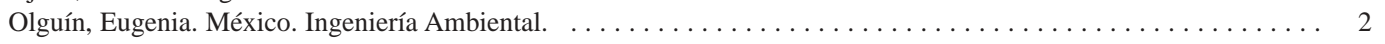

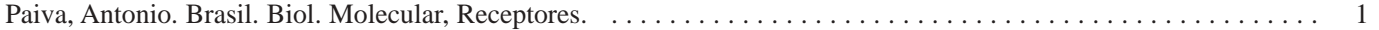

Papavero, Nelson. Sao Paulo, Brasil. Entomología Historia de la Biología. . . . . . . . . . . . . . . . . 1

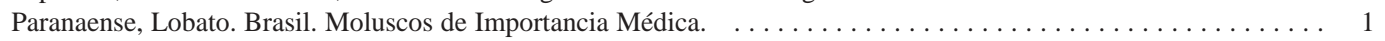

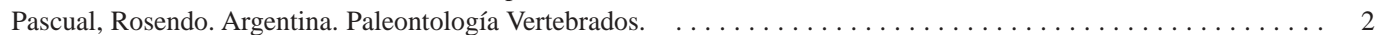

Patarroyo, Manuel E. Colombia. Medicina Tropical (Vacuna contra la Malaria). . . . . . . . . . . . . . . 2

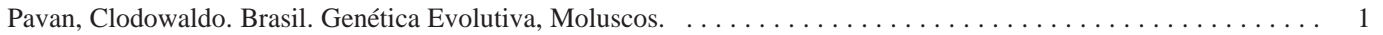

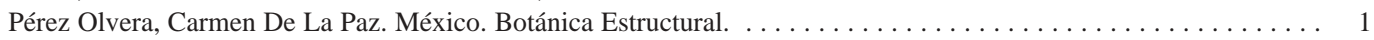

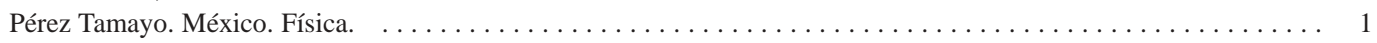

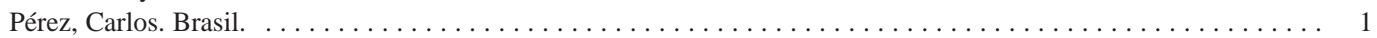

Perfecto, Ivette. Puerto Rico Diversidad en Sistemas Agrícolas. $\ldots \ldots \ldots \ldots \ldots \ldots$

Picado, Clodomiro. Costa Rica/Nicaragua. Biología, especialista en ofidismo. $\ldots \ldots \ldots \ldots$

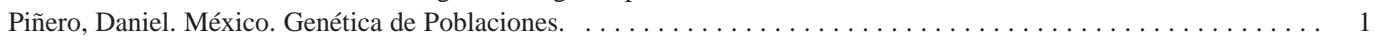

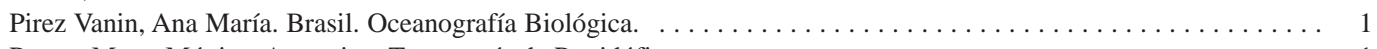

Ponce, Marta Mónica. Argentina. Taxonomía de Pteridófitas $\ldots \ldots \ldots \ldots \ldots \ldots \ldots$ 
CUADRO 2 (...continuación)

Científicos (as) más destacados (as) de América Latina según las personas consultadas (número de casos)

TABLE 2 (...continued)

Most outstanding Latin American scientists according to the survey (includes foreigners that normally work in the region)

Científico destacado/País/Área

\# Respuestas

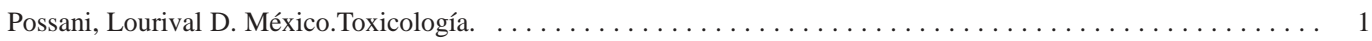

Poveda, Luis. Costa Rica. Dendrología, Biología, experto en Plantas Medicinales. $\ldots \ldots \ldots \ldots \ldots \ldots \ldots \ldots \ldots$

Rabinovich, Jorge. Argentina. Ecología. $\quad \ldots \ldots \ldots \ldots \ldots \ldots \ldots \ldots \ldots \ldots \ldots \ldots \ldots \ldots \ldots \ldots \ldots \ldots \ldots$

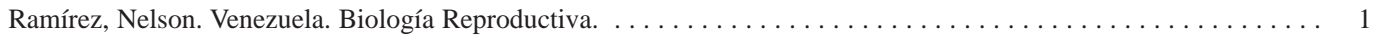

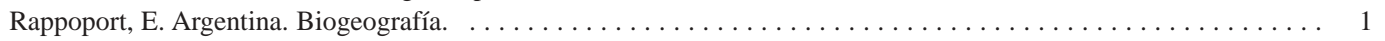

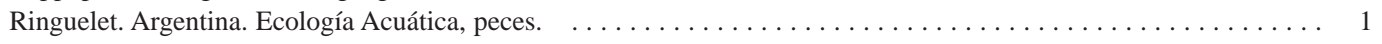

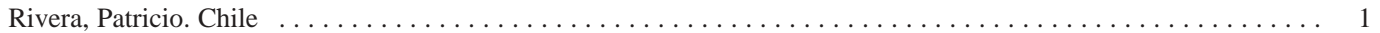

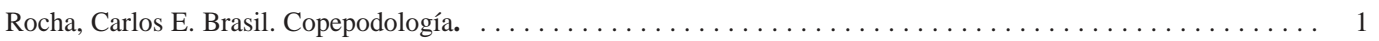

Rodríguez, Gilberto. Venezuela. Zoología de Invertebrados, crustáceos. $\ldots \ldots \ldots \ldots \ldots \ldots \ldots \ldots \ldots \ldots \ldots \ldots$

Rodríguez, Luis. UNAM, Instituto de Astronomía. Ciencias Del Espacio. $\ldots \ldots \ldots \ldots \ldots \ldots \ldots \ldots \ldots \ldots \ldots$

Rodríguez, Rafael Lucas. Costa Rica. Botánica. $\quad \ldots \ldots \ldots \ldots \ldots \ldots \ldots \ldots \ldots \ldots \ldots \ldots \ldots \ldots \ldots \ldots \ldots \ldots$

Rosseto, Franscisco Jorge. Brasil. Resistencia en Plantas. $\ldots \ldots \ldots \ldots \ldots \ldots \ldots \ldots \ldots \ldots \ldots \ldots \ldots \ldots \ldots$

Ruiz Linares, Andrés. Facultad de Medicina, Universidad de Antioquia, Colombia. $\ldots \ldots \ldots \ldots \ldots \ldots \ldots \ldots \ldots 1$

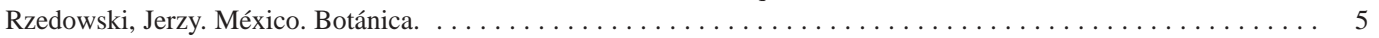

Sala,Osvaldo. Argentina. Biodiversidad y Funcionamiento de Ecosistemas, Herbivoría. $\ldots \ldots \ldots \ldots \ldots \ldots \ldots \ldots$

Salazar-Vallejo, Sergio. México. Poliquetos y Contaminación Marina. $\ldots \ldots \ldots \ldots \ldots \ldots \ldots \ldots \ldots \ldots \ldots \ldots 2$

Salibian, Alfredo. México. Ecotoxicología. $\quad \ldots \ldots \ldots \ldots \ldots \ldots \ldots \ldots \ldots \ldots \ldots \ldots \ldots \ldots \ldots \ldots \ldots \ldots \ldots$

Salzano,Francisco. Dpto. Genética, Universidad Federal de Rio Grande Do Sul, Brasil. Genética. . . . . . . . . . . 1

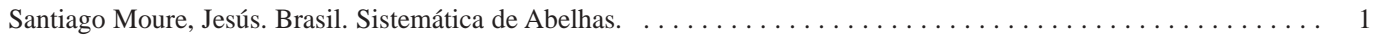

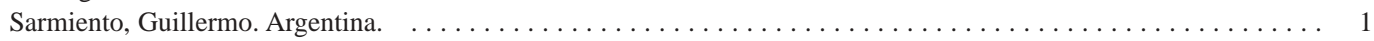

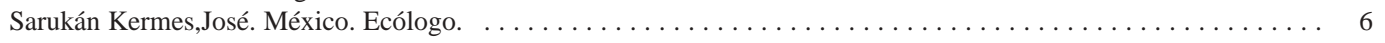

Sazima, Ivan. Brasil. Historia Natural de Vertebrados. $\ldots \ldots \ldots \ldots \ldots \ldots \ldots \ldots \ldots \ldots \ldots \ldots \ldots \ldots \ldots \ldots \ldots$.

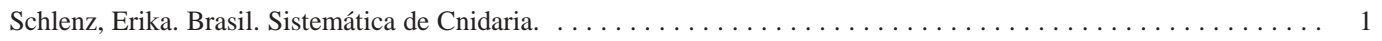

Schmitt de Melo, Gustavo. Brasil. Carcinología. $\ldots \ldots \ldots \ldots \ldots \ldots \ldots \ldots \ldots \ldots \ldots \ldots \ldots \ldots \ldots \ldots \ldots \ldots \ldots$

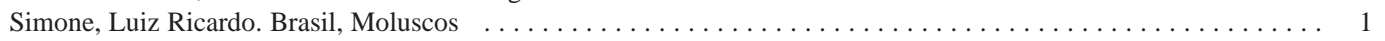

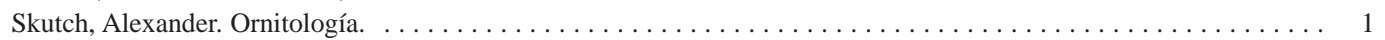

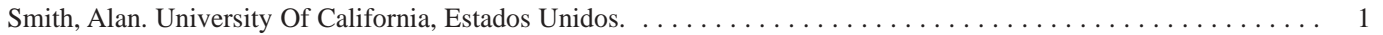

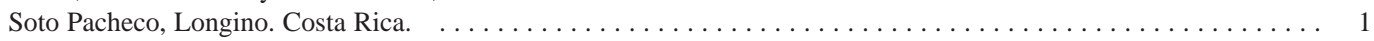

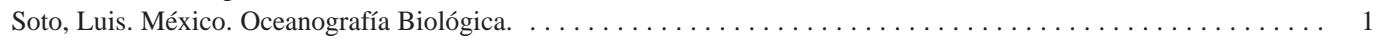

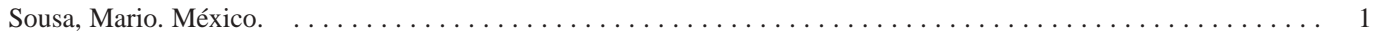

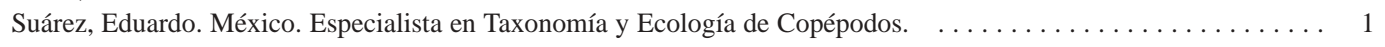

Tarazona-Santos, Eduardo. Brasil. Dpto. de Bioquímica e Inmunología, Universidad Federal Minas Gerais. . . . . . 1

Toledo Gamma, Gerardo. Estados Unidos. Ecología Microbiana de Ambientes Marinos. . . . . . . . . . . . . . 1

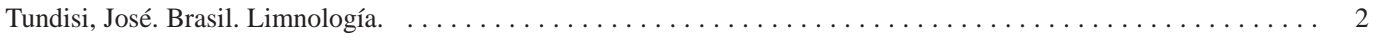

Umaña, Gerardo. Costa Rica. Limnología $\ldots \ldots \ldots \ldots \ldots \ldots \ldots \ldots \ldots \ldots \ldots \ldots \ldots \ldots \ldots \ldots \ldots \ldots \ldots \ldots$

Urbina Romero, Julio Alberto. Venezuela. Biofísica-Química. $\ldots \ldots \ldots \ldots \ldots \ldots \ldots \ldots \ldots \ldots \ldots \ldots \ldots \ldots \ldots$

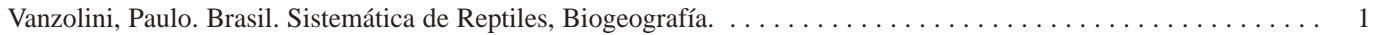

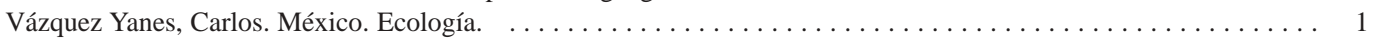

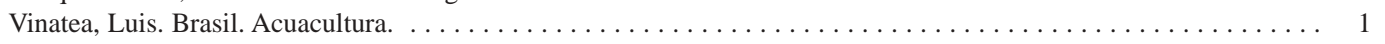

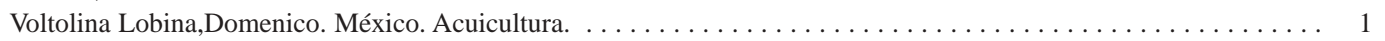

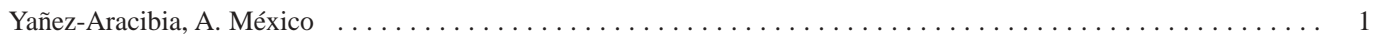

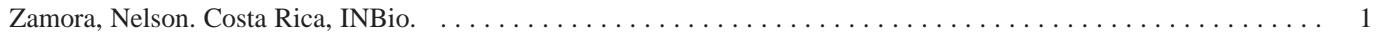

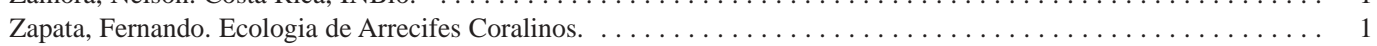

Zeledón, Rodrigo. Costa Rica. Microbiología. $\ldots \ldots \ldots \ldots \ldots \ldots \ldots \ldots \ldots \ldots \ldots \ldots \ldots \ldots \ldots \ldots \ldots \ldots \ldots$

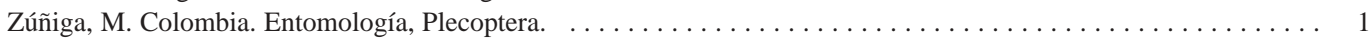


CUADRO 3

Libros científicos que más han influido en el trabajo de las personas encuestadas (número de casos)

TABLE 3

Scientific books with the greatest influence on the work of scientists who answered the survey

A Classification of the Siphonaptera of South America. Phyllis Truth Johnson.

A field guide to the mammals of Central America and Southeast Mexico. F.A. Reid.

A history of South Pacific Fishes. Giles W. Mead.

A Monograph on the Polychaeta of Southern Africa. J.H. Day.

A treatise on Limnology. G.E. Hutchinson.

Advances in Spider Taxonomy. Platnick.

African Diatoms: Taxonomy, Ecological Distribution. F. Gasse.

American Seashells. T.R. Abbott.

An introduction to agroforestry systems. P.K. Nair.

An introduction to population genetics theory. J.F. Crow \& M. Kimura.

An Introduction to the Aquatic Insects of North America. Merritt \& Cummins.

Analysis of Marine Ecosystems, A. Longhurst (ed.).

Ancient DNA. Susanne Hummel.

Animal Behavior. John Alcock.

Animal Evolution. Nielsen.

Animal Physiology. Schmidt-Nielsen.

Ants. B. Hölldobler \& E.O Wilson.

Aquaculture Economic Analysis. Yung Shang.

Aquatic Entomology. McCafferty.

Árboles de Costa Rica. L. Holdridge \& L. Poveda.

Artemia, basic and applied biology. TH.J. Abatzopoulus, J.A. Beardmore, J.S. Clegg \& P. Sorgeloos.

Atlas del zooplancton del Atlántico Sudoccidental y métodos de trabajo con el zooplancton marino. D. Boltovskoy (ed.).

Behavioural Ecology. J.R. Krebs \& N.B. Davies.

Biochemistry and Molecular Biology of Parasites. J.J. Marr \& M. Muller.

Biodiversidad Biológica de Mexico, Orígenes y Distribución, T.P. Ramamoorthy.

Biodiversity and Ecoystem Function. Tilman \& Pacala (eds.).

Bioenergetics of Aquatic Animals. Albert Lucas (ed.). Bioestatistical Analysis. J.H. Zar.

Biogeografía de América Lantina. A.L. Cabrera \& A. Willink.
Biogeographie Evolutive. Jacques Blondel.

Biogeography. Brown \& Lomolino.

Biología Centrali - Americana (Land and fresh water mollusca). E. Von, Martens.

Biologia Centraliamericana. Godman \& Salvin.

Biología. Claude Villee.

Biología. de Teresa Audesirk.

Biological Control. Van den Bosch \& Paul de Back.

Biological Diversity of México: Origins and Distribution. T.P. Ramamoorthy, et al (eds.)

Biological Oceanographic Proceses. Parsons et al.

Biology of Aquatic Plants. Sculthorpe.

Biology of Bromeliads. D.H. Benzing.

Biology of land crabs. Burggren \& Mcmahon.

Biology of Plants. Peter H. Raven, Ray F. Evert \& Susan E. Eichhorn.

Biology of Scorpions. Polis.

Biology of Ticks. D.E. Sonenshine.

Bromeliads. D.H. Benzing.

Cazadores de microbios. P. De Kruif.

Changes in marine communities: An approach to statistical analysis and interpretation. Coastal and estuarine studies. A.I. Robertson \& D.M. Alongi (eds.).

Coelenterate Biology. Lenhoff (ed).

Coelenterate Ecology and Behavior. G.O. Mackie.

Common intertidal invertebrates of the Gulf of California. Richard Brusca.

Comparative morphology of recent Crustacea. Patsy Mclaughlin.

Compendium of land shells. R.T. Abbott.

Contributions to West Indian Herpetology. (Varios autores).

Copepod Evolution. R. Huys \& G.A. Boxshall.

Coral reefs. Z. Dubinski.

Corals and coral reefs of the Galapagos Islands. Peter W. Glynn \& G.M. Wellington

Corals in Space and Time. J.E.N. Veron. Corals of the World. J.E. Veron.

Costa Rican Natural History, D.H. Janzen (ed.).

Crustaceos decápodos de Venezuela. Gilberto Rodríguez.

Darwin's dangerous idea. Daniel Dennet.

Deep Sea Biology. Gague \& Tyler. 


\author{
CUADRO 3 (...continuación) \\ Libros científicos que más han influido en el trabajo de las personas encuestadas (número de casos)
}

TABLE 3 (...continued)

Scientific books with the greatest influence on the work of scientists who answered the survey

Development and progress in sediment quality assessment. M. Munawar \& G. Dave (eds.).

Developmental Biology. S. Gilbet.

Diseases of marine animals. Otto Kinne (ed.)

Diversity of life. E.O. Wilson.

DNA markers: a global overview. A. Karp \& K. Edwards (In DNA markers: protocols, applications, and overviews. G. Caetano-Anollés \& P.M. Gresshoff (eds.).

Dynamics of Marine Ecosystems. Mann \& Lazier.

Ecologia Evolutiva. Pianka.

Ecología. Ramón Margalef.

Ecological communities. D. Strong et al.

Ecological detective. Hilbor \& Mangel.

Ecological Diversity. Huston.

Ecological Entomology Huffaker.

Ecological geography of the sea. Longhurst.

Ecological Methodology. C. Krebs.

Écologie Numérique. Pierre Legendre \& Louis Legendre.

Ecology and Management of Coastal Waters. G. Bernabe $\&$ R. Bernabe-Quet.

Ecology of Coral Reef Fishes. Peter Sale.

Ecology. E.P. Odum.

Ecology. Individuals, Populations and Communities. Begon, Harper y Townsend. (eds).

Ecology. Smith.

Ecosistemas de manglar en América tropical. A. YañezArancibia \& A.L. Lara-Dominguez (eds.).

Ecosystems of the World 25. Coral reefs. Z. Dubinsky (ed.).

El mundo y sus demonios. La ciencia como una luz en la oscuridad. Carl Sagan.

El Niño, experimento climático de la Naturaleza. Artnz \& Fahrbach.

El pulgar del panda. Stephen Jay Gould.

Enciclopedia Fauna. Félix Rodríguez de la Fuente.

Entomology in Human and Animal Health. R.F. Harwood \& M.T. James.

Environmental Coastal Regions. C.A. Brebbia (ed.)

Estadística Aplicada. Sach.

Estadistica no paramétrica. E. Siegel.

Ethics in the Ark. Mike Hutchins.

Evolution as entropy. D.R Brooks.
Evolutionary Biology. Futuyma.

Exegetics. Sin otros datos.

Familias de plantas neotropicales. P.J.M. Maas \& L.Y.Th. Westra.

Fauna of the USSR. Crustacea Chydoridae. N.N. Smirnov.

Ferns and allied plants, with special reference to tropical America. R.M. Tryon \& A.F. Tryon.

Fidler Crabs of the World. Crane.

Fish Population Dynamics in Tropical Waters. Daniel Pauly.

Fisheries Stock Assessment. Hilborn \& Walters.

Fishes of the world. Joseph Nelson.

Fishes: an introduction to Ichthyology. Moyle \& Cech.

Flora de Nicaragua. Sin otros datos.

Flora Mesoamericana. Sin otros datos.

Flora Mesoamericana. Robbin C. Moran \& Ramón Riba (eds.).

Flora of Guatemala. Sin otros datos.

Foraging Theory. D. Stephens \& J.R. Krebs.

Forest stand dynamics. Oliver \& Larson.

Freshwater Biology. W.T. Edmonson.

Frogs of Colombia. D. Cochran \& Goin.

Fundamentals of Aquatic Toxicology. Rand \& Petrocelli.

Fundamentos de Limnología Neotropical. Gabriel Roldán.

Géneros de orquídeas de Costa Rica. R.L. Rodríguez, et al. Genes. B. Lewin.

Guns-germs-and-steel. Jared Diamond.

Hamlet. W. Shakespeare.

Handbuch der zoologie, Lepidoptera, Moths and Butterflies. Niels P. Kristensen (ed.)

Herpetology. Pough et al.

Historia Natural de Costa Rica. D.H. Janzen (ed.).

Illustrated Catalogue of the Rothschild Collection of Fleas. G.H.E. Hopkins \& Miriam Rothschild.

Infectious Diseases and Arthropods. Jerome Goddard.

Inland Fishery Enhancements. F.A.O.

Inland Waters of Tropical Africa. L.C. Beadle.

Insect Pathology. Y. Tanada \& H. Karra.

Integrative Plant Anatomy. W. Dickinson.

Introduction to Biochemical Toxicology. Hodgson \& Levy. 
CUADRO 3 (...continuación)

Libros científicos que más han influido en el trabajo de las personas encuestadas (número de casos)

TABLE 3 (...continued)

Scientific books with the greatest influence on the work of scientists who answered the survey

Invertebrate Zoology. Barne.

Invertebrate Zoology. Richard Brusca \& Gary Brusca.

Ionic channels of excitable membranes. B. Hille.

La estructura de las revoluciones cientificas. Thomas $\mathrm{S}$

Kuhn.

La Nueva Sintesis. E. Mayr.

Land Mollusca of North America (north of México). H.A. Pilsbry.

Land Mosaics. R.T.T. Forman.

Latin America insects and entomology, C. Hogue.

Life Above the Jungle Floor. Donald Perry.

Life and Death of Coral Reefs. Charles Birkeland.

Limnoecology, W. Lampert \& U. Sommer.

Limnología de embalses. R. Margalef.

Limnology. Robert Wetzel.

Lizards of Brazilian Amazonia. T. Avila-Pires.

Los peces marinos de Venezuela. Fernando Cervigon.

Mammal Species of the World. D.E. Wilson \& D.M. Reeder.

Mammals of north America. Hall.

Mammals of the World. Walker.

Manual de Entomologia Agricola. Domingo Gallo et al.

Manual de identificação dos Brachyura (caranguejos e siris) do litoral brasileiro. G.A.S. Melo.

Manual of Nearctic Diptera (numerosos autores)

Manual of the culture and use of the brine shrimp Artemia in aquaculture. P. Sorgeloos, P. Lavens, P. Leger, W. Tackeart \& D. Versichele.

Marine Biogeochemistry. Susan M. Libes.

Marine Biology, Fuction, Biodiversity and Ecology. J.S. Levinton.

Marine Shrimp Culture: Principles and Practices. A.W. Fast \& L.J. Lester (eds.)

Marine zoogeography. J.C. Briggs.

Matrix population models. H. Caswell.

Mayflies of North and Central America. Edmunds et al.

Medicina Legal. J.A. Gisbert Calabuig.

Metal pollution in the aquatic environment. Forstner \& Wittmann.

Methods in marine zooplankton ecology. D. Boltovskoy (ed.).

Modelling Forest Growth and Yield applications to mixed tropical forest. J.K. Vanclay.
Molecular Cell Biology. Darnell, Lodish \& Baltimore.

Molecular evolution phylogenetics. Masatoshi Nei \& Sudhir Kumar.

Molecular markers, natural history and Evolution. J.C. Avise.

Molecular systematic. Hillis, Moritz \& Marble.

Molecular Systematics. Moritz \& Hillis.

Molecular tools for screening biodiversity. A. Karp, P.G. Issac \& D.S. Ingram (eds.).

Moluscos del Caribe colombiano. J.M. Díaz \& M. Puyana.

Noah's flood. William Ryan \& Walter Pitman.

Numerical Ecology. Pierre Legendre \& Louis Legendre.

Oceanography. Neshyba.

Ontogeny and systematics of fishes. G. Moser et al.

Origen de las especies / The origin of species by means of Natural Selection. Charles Darwin.

Ornithology. Gill. Paleolimnology. Andrew Cohen.

Panbiogeography, R.C. Craw.

Parasitism. Bush, Fernández, Esch \& Seed.

Parasitología general. CHENG.

Patterns of Distribution of Amphibians. W. Duellman (ed.).

Phylogenetic Systematics W. Hennig.

Phylogeny, ecology, and behavior. D.R. Brooks.

Phylogeography. J. Avise.

Physiological Bases of Phytoplankton Ecology. Platt.

Phytoplankton Ecology. Collin Reynolds.

Plant - animal interactions: evolutionary ecology in tropical and temperate regions. P.W. Price.

Plant Breeding Systems. A.J. Richards.

Plant Ecology. M.J. Crawley (ed.).

Plant propagation by tissue culture. The technology. E.F. George.

Plant Stem: Physiology and Functional Morphology. B. Gartner.

Plant Systematics. Judd. et al.

Poissons, In Traité de Zoologie. P.P. Grassé.

Poliquetos de México. Salazar Vallejo et al.

Pontellid Copepods of the Gulf of Mexico. A. Fleminger.

Primary Productivity in the Oceans. Raymont.

Principles of Biochemistry. Albert Lehninger.

Principles of conservation biology. Meffe \& Carroll. 


\author{
CUADRO 3 (...continuación) \\ Libros científicos que más han influido en el trabajo de las personas encuestadas (número de casos)
}

TABLE 3 (...continued)

Scientific books with the greatest influence on the work of scientists who answered the survey

Principles of Insect Pathology. D. Boucias \& J. Pendland.

Principles of Insect Pathology. Steinhaus.

Principles of neural science. Kandel, Schwartz, Jessell.

Principles of population genetics. D.L. Harttl \& A.G. Clark.

Principles of Systematic Zoology. E. Mayr.

Principles of Toxicology. Walker, S. P. Hopkin, R. M. Sibly \& D. B. Peakall.

Pteridophytes of Oaxaca, México, J. T. Mickel \& J. Beitel.

Reef Evolution. Reachel Wood.

Reef fisheries. N. Polunin \& C.M. Roberts (eds.).

Scallops: biology, ecology and aquaculture. Sandra Shumway.

Sea Turtle Biology and Conservation. Bjorndal.

Sediment Toxicity Assessment. A. Burton.

Sexual Selection and Animal Genitalia. W. Eberhard.

Shrimps, lobsters, and crabs of the Atlantic coast of the eastern United States, Maine to Florida. A.B. Williams.

Sistemas agroforestales. Principios y aplicaciones en los trópicos. Florencia Montagnini.

Snakes: the evolution of mystery in nature. H.W. Greene. Sociobiologia. E.O. Wilson.

South Altantic Zooplankton. D. Boltovskoy (ed.).

Souvenirs Entomologiques. Jean-Henri Fabre.

Species diversity in space and time. M.L. Rosenzweig.

Spiders and their kin. Levi.

Standard methods for nutrition and feeding of farmed fish and shrimp. A.W.A. Tacon.

Statistical Ecology. Ludwig \& Reynolds.

Stream Ecology. Allan.

Suelos del trópico húmedo. Pedro Sánchez.

Systematik und faunistik der pelagischen copepoden des Golfes von Neapel und der angrezenden meeresabschnitte. Fauna und Flora Golfes von Neapel. Giesbrecht, W.

Techniques for Pollination Biologists. Kearns \& Ionuye.

Teoría de los Sistemas Ecológicos. Ramón Margalef.

The amphibians and reptiles of Costa Rica: A herpetofauna between two Continents, two Seas, J.M. Savage.

The Bees of the World. C.D. Michener.

The Biology of Disease Vectors. (numerosos autores)

The biology of pelagic tunicates. Q. Bone (ed.).
The biology of the euphausiids. J. Mauchline \& L.R. Fisher. In F.S. Russell \& M. Younge (eds.). Advances in marine biology.

The Botany of mangroves. P.B. Tomlinson.

The Descent of Man and Selection in Relation to Sex. C. Darwin.

The distribution of Pacific euphausiids. E. Brinton.

The diversity of life. E.O. Wilson.

The Ecology of Ectoparasitic Insects. Marshall.

The Ecology of Fishes on Coral Reefs. Sale.

The Ecology of Rocky Shores. J.R. Lewis.

The ecology of running waters. Hynes.

The Evolution of Insect Mating Systems. R. Thornhill \& J. Alcock.

The families and genera of vascular plants. Pteridophytes and Gymnosperms. K.U. Kramer \& P.S. Green (eds.).

The ferns and fern-allies of Costa Rica, Panama and the Chocó. David B. Lellinger.

The Fragmented Forest. Larry Harris.

The Glossary for Entomology. Torre-Bueno.

The Insect Societies. Edward O. Wilson.

The insects. Chapman.

The Lepidoptera, form, function, and diversity. Malcolm J. Scoble.

The little ice age. Brian Fagan.

The logic of scientific discovery. Karl Popper.

The Natural history of the Tropical bees. David Roubik.

The Naturalist on the River Amazons. Henry W. Bates.

The pharmacological basis of therapeutics. Goodman \& Gilman.

The practice of silviculture: applied forest ecology. Smith et al. The Selfish Gene. Richard Dawkins.

The social behavior of Bees. Charles Michener.

The South American Herpetofauna: its origin, evolution and dispersal. W. Duellman.

The Tropical Oceans. A. Longhurst.

The tropical rain forest. P.W. Richards.

The venomous reptiles of Latin America. J.A. Campbell \& W.W. Lamar.

This is biology. E. Mayr.

Toxicology. The basic Science of poisons. Casarett \& Doull. 
CUADRO 3 (...continuación)

Libros científicos que más han influido en el trabajo de las personas encuestadas (número de casos)

TABLE 3 (...continued)

Scientific books with the greatest influence on the work of scientists who answered the survey

Trophic Models of Aquatic Ecosystems. V. Christenesen \& D. Pauly (eds.).

Tropical Ecology. P.W. Richads.

Tropical nature. Adrian Forsyth \& Ken Miyata.

Tropical rain forest ecophysiology. S.S. Mulkey, R. Chazdon \& A. Smith.

Un naturalista en el Amazonas. H.W. Bates.

Vascular Epiphytes. D.H. Benzing.

Veterinärmedizinische Parasitologie. Boch \& Supperer.

Viaje a las regiones equinocciales. A. v. Humbolt.

Viaje por el Amazonas. R. Wallace.

Biología Tropical (108 respuestas), Ciencias Marinas (28), Revista Chilena de Historia Natural (14), Interciencia (12), Anales del Instituto de Biología de la UNAM (10), Caribean Journal of Science (10), Biotropica (9) y Acta Botánica Mexicana, Acta Zoológica Mexicana y Memorias do Instituto Oswaldo Cruz (6 casos cada una). Otras revistas solo fueron mencionadas por muy pocas personas (Cuadro 4).

\section{DISCUSIÓN}

A pesar de que la participación en el estudio era voluntaria, la encuesta tuvo una buena tasa de respuesta pues fue respondida por aproximadamente uno de cada tres encuestados. Posibles razones son el alto nivel educacional de las personas consultadas (que por ende comprenden el valor de este tipo de estudios); la brevedad de la encuesta y el hecho de que el cuestionario era fácil de devolver por vía electrónica.

Revistas más influyentes en la labor científica: Con excepción de la Revista de Biología Tropical, la mayoría de las revistas repetidamente mencionadas como más influyentes en la labor científica fueron revistas de países desarrollados. Temáticamente, se mencionaron
Vida de los peces en aguas chilenas. Guillermo Mann.

Wetlands. Mitsh \& Gosselink.

Wonderful Nature, S.J. Gould

World wide snails. Alan Solem \& A.C. Van Bruggen.

Xylem Structure and the ascent of sap. Springer. Zimmerman, Tyree.

Zoología de los invertebrados. R. Barnes.

ZooMan, Terry Maple. Nota: se transcriben las respuestas con ligeras correcciones. Si las respuestas incluían tanto el original como traducciones de los libros, aparecen ambos.

especialmente revistas del área marina y ecológica. Aparentemente, el estudio de los ecosistemas costeros está más desarrollado que el estudio de los ecosistemas terrestres, lo cual es explicable por la concentración de población, actividad económica y problemas ecológicos latinoamericanos a menos de 100 kilómetros de la costa (Cohen et al. 1997, Anónimo 2002). Estos resultados sugieren la necesidad de que las revistas latinoamericanas hagan un esfuerzo para llenar mejor las necesidades del aparato científico regional. Estas mejoras básicamente incluirían buena atención a los autores, un estricto rechazo de los manuscritos de inferior calidad, y una distribución a tiempo y muy amplia de las revistas (Monge-Nájera et al. 2003).

Investigadoras e investigadores más influyentes: A diferencia de la ciencia estadounidense, no hay personajes que sobresalgan de manera apabullante. Aun si este resultado reflejara la gran cantidad de especialidades dentro de la población consultada, dejando abierta la posibilidad de que sí existan personalidades muy reconocidas dentro de ramas particulares como la microbiología o la genética, se mantiene el resultado general: no parece haber "superestrellas" dentro de la biología latinoamericana. Este resultado, respaldado por una encuesta, resalta la subjetividad de premios y calificaciones en este campo. Por ejemplo, 
CUADRO 4

Principales revistas científicas de América Latina según las personas encuestadas (número de casos)

TABLE 4

Main Latin American scientific journals according to scientists who answered the survey

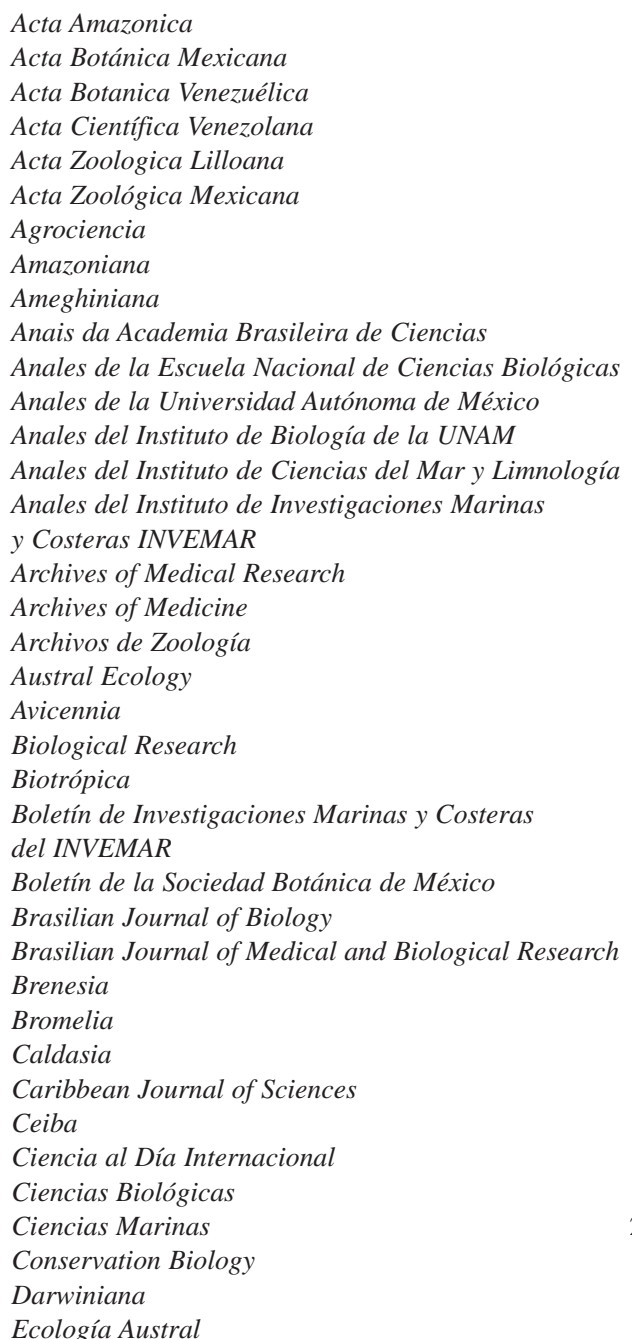

ninguna de las personas de la lista de "varios de los más prestigiados científicos latinoamericanos" de Vega (2002) fue mencionada en la encuesta como investigadora destacada (Cuadro 2).

Posibles causas de la ausencia de "superestrellas" son que en América Latina no hay tradición de que mujeres y hombres de ciencia locales aparezcan frecuentemente en los medios, que se tiene poca capacidad de difundir

$\begin{array}{lr}\text { Entomotropica } & 1 \\ \text { Geofísica Internacional } & 2 \\ \text { Hidrobiologia } & 4 \\ \text { Hidrobiológica } & 2 \\ \text { Iheringia } & 1 \\ \text { Interciencia } & 12 \\ \text { Investigaciones Marinas, CICIMAR } & 1 \\ \text { Journal of Brasilian Genetics } & 1 \\ \text { Lankesteriana } & 1 \\ \text { Memorias del Instituto de Butantan } & 1 \\ \text { Memorias do Instituto Oswaldo Cruz } & 6 \\ \text { Nauplius } & 2 \\ \text { Neotropica } & 1 \\ \text { Neotropical Entomology } & 3 \\ \text { Novon } & 1 \\ \text { Oceánides } & 1 \\ \text { Papeis Avulsos de Zoología } & 1 \\ \text { Pesquisa Agropecuaria Brasileira } & 1 \\ \text { Physis } & 1 \\ \text { POEYANA } & 1 \\ \text { Polibotánica } & 1 \\ \text { Revista Brasileira de Biologia } & 1 \\ \text { Revista Brasileira de Botánica } & 1 \\ \text { Revista Brasileira de Zoología } & 1 \\ \text { Revista Chilena de Historia Natural } & 1 \\ \text { Revista de Biología Tropical } & 1 \\ \text { Revista de la Academia Colombiana de } & 1 \\ \text { Ciencias Exactas, Fisicas y Naturales } & 1 \\ \text { Revista de la Sociedad Entomológica Argentina } & 1 \\ \text { Revista del Instituto de Medicina Tropical } & 1 \\ \text { de Sao Paolo } & 1 \\ \text { Revista Internacional de Contaminación Ambiental } & 1 \\ \text { Revista Latinoamericana de Microbiología } & 3 \\ \text { Revista Mexicana de Mastozoología } & 1 \\ \text { Revista Mexicana de Micología } & 1 \\ \text { Revista Nicaragüense de Entomologia } & 1 \\ \text { Turrialba } & 1 \\ \text { Verhandlungen, International Verein Limnologiae } & 1 \\ \text { Vida Silvestre Neotropical } & \\ & 1 \\ \end{array}$

internacionalmente los resultados locales y la insignificante importancia que la cultura iberoamericana concede a la ciencia (en comparación con otras áreas del quehacer humano como el arte o la literatura).

La marcada dominancia del sexo masculino puede deberse a que hay pocas mujeres trabajando en este campo o a que ellas no sean percibidas como sobresalientes por razones de inequidad sociocultural (Villarreal 2001). 
La predominancia de nacionalidades de las personas consideradas como influyentes en la ciencia latinoamericana calzan en general con los países que dominan la producción científica regional (Vessuri 1987, Castro 1998).

Las especialidades más mencionadas para personas influyentes no corresponden directamente con la predominancia de artículos publicados en la Revista de Biología Tropical durante los últimos 5 años, donde la Zoología (60.3\%), Botánica (20.1\%), Ecología (10.2\%) y Biomedicina (4.8\%; fuente: registro interno de la revista) dan cuenta de la mayoría de las publicaciones. Esto descarta la posibilidad de un sesgo entre los científicos consultados por ser de alguna manera próximos a la revista.

Libros más influyentes: La ausencia de uno o unos pocos libros que tuvieran una influencia muy marcada es sorprendente, ya que en otros países se ha encontrado que sí hay obras que influyen destacadamente sobre una o varias generaciones (Summers 1998).

En cambio, la preponderancia de los libros escritos en inglés era de esperar por ser este el idioma científico predominante desde hace más de un siglo.

Los temas de los libros en general coinciden con las especialidades mencionadas para las personas más influyentes en la ciencia latinoamericana, lo que probablemente refleje las áreas científicas de mayor interés o desarrollo en la región.

Principales revistas científicas de América Latina: La Revista de Biología Tropical dominó claramente, seguida de lejos por otras revistas que son principalmente mexicanas. Podría pensarse que este resultado se debe a que la encuesta se distribuyó entre personas del área científica que han tenido alguna relación con la revista como autores o revisores (y por ello han sido incluidas en la base de datos de referencia para este estudio). Sin embargo, fuentes independientes también han reconocido a Biología Tropical como la principal revista biológica regional (Hastings y Robertson 2001) o como una de las más importantes (Salazar-Vallejo y Carrera-Parra 1998, Cazaux
2002, Pacheco-Ruíz y Quintanilla-Montoya 2002, CAPES 2003), lo que sugiere que la revista realmente es reconocida como dominante dentro del Neotrópico. Esto es sorprendente considerando la poca importancia poblacional, económica y científica del país base, Costa Rica: se esperaría que las revistas líderes provinieran de los gigantes regionales, Brasil, México y Argentina.

Posibles causas de esta excepción al patrón esperado son la larga tradición de la revista y la escasa disponibilidad de otras alternativas especializadas en el ámbito tropical con equivalente difusión y periodicidad. Además, la inclusión y permanencia de la revista en los conocidos y difundidos índices internacionales puede estar siendo interpretada por los autores como una ventana a la corriente principal de la ciencia, ventana que es fácilmente asequible a los investigadores latinoamericanos por la identificación o proximidad cultural, idiomática y geográfica. Esto puede estar a la vez relacionado con la creciente exigencia por publicar en revistas "indexadas" (o sea, incluidas en índices internacionales) que experimentan algunos grupos de investigadores debido a los sistemas de acreditación de calidad. Estos sistemas, junto a incentivos salariales, se han venido estableciendo países de la región como México, con la intención de mejorar su productividad científica.

En síntesis, los resultados de esta encuesta nos plantean la necesidad de que América Latina desarrolle un panteón propio de héroes, quienes puedan servir como gestores de un desarrollo científico que obedezca a las necesidades regionales y locales, que sirvan como catalizadores de la incorporación y consolidación de la ciencia dentro de la cultura iberoamericana, y más importante aún, que sirvan de modelos a las nuevas generaciones.

\section{AGRADECIMIENTOS}

Agradecemos a las 152 personas que tuvieron la amabilidad de responder nuestras preguntas. 


\section{RESUMEN}

Para identificar las revistas, libros y personas más influyentes en la biología latinoamericana, se envió por correo electrónico una encuesta a 553 personas dedicadas el tema, según la base de datos de la Revista de Biología Tropical. Un tercio de ellas respondió, concluyéndose que la Revista de Biología Tropical, es la más influyente de la región según las personas consultadas. Con esta excepción. la mayoría de las revistas influyentes son publicadas en países desarrollados. La distribución temática de las respuestas y las evaluaciones independientes descartan la posibilidad de que este y los demás resultados resulten de un sesgo entre los científicos consultados por ser de alguna manera próximos a la revista. Temáticamente, se mencionaron especialmente revistas del área marina y ecológica. A diferencia de la ciencia estadounidense, no hay personajes ni libros influyentes que sobresalgan de manera apabullante. Los resultados resaltan la subjetividad de premios y calificaciones en este campo y posiblemente resulten de que no hay tradición de que mujeres y hombres de ciencia locales aparezcan frecuentemente en los medios de comunicación, la poca capacidad de difundir internacionalmente los resultados locales y la insignificante importancia que la cultura iberoamericana concede a la ciencia. También sugieren la necesidad de que las revistas latinoamericanas hagan un esfuerzo para llenar mejor las necesidades del aparato científico regional (buena atención a los autores, un estricto rechazo de los manuscritos de inferior calidad, y una distribución a tiempo y muy amplia de las revistas). La marcada dominancia del sexo masculino puede deberse a que hay pocas mujeres trabajando en este campo o a que ellas no sean percibidas como sobresalientes por razones de inequidad sociocultural. La predominancia de nacionalidades de las personas consideradas como influyentes en la ciencia latinoamericana calzan en general con los países que dominan la producción científica regional. El curioso hecho de que la revista más influyente sea editada en uno de los países más pequeños de la región podría deberse actualmente a la larga tradición de la revista y la escasa disponibilidad de otras alternativas con equivalente difusión y periodicidad, así como a su permanencia en los índices internacionales. Se recomienda que América Latina elija y fortalezca a sus mejores revistas y que desarrolle un panteón propio de héroes que, con el apoyo de los medios de comunicación de masas, sirvan de modelo a las nuevas generaciones

\section{REFERENCIAS}

Anónimo. 2002. Perspectivas del medio ambiente mundial 2002, GEO-3. Pasado, presente y futuro. Programa de Naciones Unidas para el Medio Ambiente, Nairobi, Kenia. 446 p.
Calvo H., M. 2003. La noticia de ciencia en el tercer mundo. Universidad de Sao Paulo, Brasil (consultado el 9 octubre 2003, www.eca.usp.br/nucleos/njr/espiral /morea15.htm).

CAPES (Coordinación de Perfeccionamiento de Personal de Nivel Superior). 2003. Periodicos. Ministerio de Educación, Brasilia (consultado el 01 Marzo 2004, http://www.capes.gov.br).

Castro, R.C.F. 1998. La representatividad de la literatura latinoamericana y del Caribe en la base de datos LILACS. Organización de Estados Americanos, Washington, D.C. (consultado el 9 de octubre 2003, www.science.oas.org/ricyt/biblioteca/documentos /castro.doc).

Cazaux, D. 2002. Latindex: el índice de las publicaciones científicas latinoamericanas. Scientific American. Latinoamérica 1(2): 20-23.

Cohen, J.E., C. Small, A. Mellinger, J. Gallup \& J. Sachs. 1997. Estimates of coastal populations. Science 278 1211-1212.

Cole, S. 1975. Leakey's Luck: The Life of Louis Seymour Bazett Leakey, 1903-1972. Collins, Londres. 448 p.

Fuentes, B. 1997. La ciencia en el tercer mundo. Bol. Soc. Mex. Física 10: 71-73

Kruif, P. de. 1954. Microbe hunters. Harcourt Brace Jovanovich, Orlando, Florida. 337 p.

Hastings. P.A. \& D.R. Robertson. 2001. Systematics of Tropical Eastern Pacific Fishes. Rev. Biol. Trop. 49(1): x-xii.

Monge-Nájera, J. 2002. Cómo hacer ciencia en los trópicos. Rev. Biol. Trop. 50: XIX-XXVIII.

Monge-Nájera, J. 2003. Os objetivo das revistas tropicales. Informatiovo da Sociedade Entomológica do Brasil 28(3): 1, 3 .

Monge-Nájera, J., C. Benavides-Varela \& B. Morera. 2003. Un nombre para Biología Tropical. Rev. Biol. Trop. 51: 617-620.

Morehouse, W. 1984. Fundamental research and frontier technologies in the Third World: new imperatives and new paradigms. Interciencia 9: 140-144.

Pacheco-Ruíz, I. \& A.L. Quintanilla-Montoya. 2002. La revista Ciencias Marinas y su factor de impacto mundial / The journal Ciencias Marinas and its worldwide impact factor. Ciencias Marinas: 121-124. 
Redondo B., L. 2003. Retos ante la Ciencia Política Tercermundista. La investigación. (consultado el 12 setiembre 2003, http://www.nodo50.org/cubasiglo XXI/politica/redondo3_310701.htm).

Salazar-Vallejo, S.I. \& L.F. Carrera-Parra. 1998. Taxonomía biológica, factor de impacto y evaluación curricular para el siglo XXI. Interciencia 23: 293-298.

Summers, W.C. 1998. Microbe Hunters revisited. Internatl. Microbiol. 1: 65-68.
Vega, P. 2002. Nuevo espacio para la ciencia latinoamericana. Universidad Nacional Autónoma, México, D.F., México. (consultado el 12 setiembre 2003, http://www.jornada.unam.mx/2002/may 02 /020520/cien-patricia.html).

Villarreal, A.L. 2001. Relaciones de poder en la sociedad patriarcal. Actualidades Investigativas en Educación, Universidad de Costa Rica, San José, Costa Rica. (consultado 23 noviembre 2003, http://revista.iimec .ucr.ac.cr/articulos/1-2001/archivos/patriarcal.pdf).

\section{APÉNDICE 1}

\section{Encuesta base del estudio}

\section{Consulta de la Revista de Biología Tropical}

El volumen 51 de la Revista de Biología Tropical publicará el resultado de esta breve encuesta. Por favor responda a este mensaje llenando los espacios indicados. Su opinión ayudará a definir políticas para los próximos años.

Las tres revistas científicas que más influyen en mi trabajo son:

Hasta donde sé, los tres científicos (as) más destacados (as) de América Latina son (además del nombre, indique si es posible país y especialidad):

Los tres libros científicos que más han influido en mi trabajo son (título y si es posible, autor):

Opino que las tres principales revistas científicas de América Latina son: 
